\title{
Spatial patterns of phytoplankton composition and upper-ocean biogeochemistry do not follow carbonate chemistry gradients in north-west European Shelf seas
}

\section{Ribas-Ribas ${ }^{1,2}$, G. L. Cripps ${ }^{1}$, M. Townend ${ }^{1}$, A. J. Poulton ${ }^{3}$ and T. Tyrrell ${ }^{1}$}

[1] [Ocean and Earth Science, University of Southampton, National Oceanography Centre Southampton, Southampton, United Kingdom]

[2] [Carl von Ossietzky Universität Oldenburg, Institute for Chemistry and Biology of the Marine Environment, Wilhelmshaven, Germany]

[3] [Ocean Biogeochemistry and Ecosystems, National Oceanography Centre, Waterfront Campus, Southampton, United Kingdom]

Correspondence to: M. Ribas-Ribas. Email: mariana.ribas.ribas@uol.de, Phone: +494421944164, Fax: +494421944140

\begin{abstract}
A key difficulty in ocean acidification (OA) research is to predict its impact after physiological, phenotypic and genotypic adaptation has had time to take place. Observational datasets can be a useful tool in addressing this issue. During a cruise in June-July 2011, measurements of upper-ocean biogeochemical variables, climatically active gases and plankton community composition were collected from northwestern European seas. We used various multivariate statistical techniques to assess the relative influences of carbonate chemistry and other environmental factors on these response variables. We found that the spatial patterns in plankton communities were driven more by nutrient availability and physical variables than by carbonate chemistry. The best subset of variables able to account for phytoplankton community structure was the euphotic zone depth, silicic acid availability,
\end{abstract}


mixed layer average irradiance and nitrate concentration (59\% of variance explained). The spatial variations in phytoplankton and coccolithophores species composition were both found to be more strongly associated with nutrients and physical variables than carbonate chemistry, with the latter only explaining $14 \%$ and $9 \%$ of the variance, respectively. The plankton community composition and contribution of calcifying organisms was not observed to change under lower calcite saturation state $(\Omega)$ conditions, although no regions of undersaturation $(\Omega$ $<1)$ were encountered during the cruise. Carbonate chemistry played a more prominent, but still secondary, role in determining dinoflagellate and diatom assemblage composition (20\% and $13 \%$ of total variance explained, respectively). Nutrient and physical variables also explained more of the spatial variations of most climatically-active gases and selected biogeochemical response variables, although some also appeared to be influenced by carbonate chemistry. This observational study has demonstrated that ocean acidification research needs to be set in context with other environmental forcing variables to fully appreciate the primary, or indeed secondary, role that increasing $f \mathrm{CO}_{2}$ has on biological communities and associated biogeochemical rates.

\section{Keywords}

Ocean Acidification, Carbonate Chemistry, Nutrients, Shelf Seas, Climatically Active Gases, Biogeochemical Variables, Diatoms

\section{Introduction}

The ongoing increase in seawater $\mathrm{CO}_{2}$ and reduction in seawater $\mathrm{pH}$ associated with the uptake of fossil fuel-derived $\mathrm{CO}_{2}$ from the atmosphere (often termed ocean acidification [OA]) will have many direct and indirect effects on the chemistry and biology of the ocean 
(Shi et al., 2010). Coastal economies, including those along the coast of northwest Europe, are often dependent on calcium carbonate-producing organisms, such as shellfish (e.g., cockles, mussels, and oysters). It has been observed that in some areas elsewhere in the world these fisheries are collapsing due to changing carbonate chemistry composition (Dickson, 2010; Callaway et al., 2012). For at least nine years, the US and Mexico West Coast shellfish industry has observed high larval mortality in hatcheries and poor larval recruitment success for some species in the wild, especially during periods of strong deep-water upwelling (Cooley and Doney, 2009; Dickson, 2010).

Previous work on $\mathrm{OA}$ has also suggested that impacts are not limited to seafloor organisms, but can also affect organisms and biogeochemical processes in open water away from the coast. There is no clear agreement, heavily debated on either side, whether planktonic calcifying organisms are negatively or positively impacted. Coccolithophores are an example of calcifying organisms that have shown relatively mixed responses from OA (Riebesell et al., 2000; Iglesias-Rodriguez et al., 2008; Langer et al., 2009; Bach et al., 2015). Other marine phytoplankton (e.g., diatoms) have also been shown to change their elemental composition $(\mathrm{C} / \mathrm{N} / \mathrm{P})$ in response to changing $\mathrm{CO}_{2}$ concentration, but again these changes are species-specific and sometimes opposite responses are obtained in different studies (Engel et al., 2005; Schulz et al., 2008). It has been proposed that increasing levels of $f \mathrm{CO}_{2}$ in the surface ocean will lead to accumulation of dissolved organic carbon (DOC) and transparent exopolymer particles (TEP), with important implications for the functioning of the marine carbon cycle (MacGilchrist et al. (2014) and references therein).

Primary production also has the potential to be affected by OA. For example, during a summer 2014 cruise on the northwest European Shelf (the same cruise as is the subject of this paper), considerable variability in carbon-fixation dynamics (such as growth rates and the contribution from small cells) in manipulation experiments were observed (Richier et al., 
2014). It was also found that the net production of particulate organic carbon (POC) was strongly correlated with net changes in $\mathrm{CO}_{2}$ level.

During the same bioassay experiments as in Richier et al. (2014), an association was found between higher nitrous oxide $\left(\mathrm{N}_{2} \mathrm{O}\right)$ concentrations and lower temperatures, which was attributed to increased gas solubility (Clark et al., 2014). Furthermore, a consistent increase in dimethyl sulfide (DMS) and a decrease in the precursor dimethyl sulfoniopropionate (DMSP) in response to high $\mathrm{CO}_{2}$ was also observed (Hopkins and Archer, 2014). However, other studies previously observed a decrease in DMS under high $\mathrm{CO}_{2}$ concentrations (Hopkins et al., 2010) or no effect of elevated $\mathrm{CO}_{2}$ on concentration of DMSP (Lee et al., 2009).

To maximize our understanding of the effects of environmental stressors on complex oceanic ecosystems and biogeochemical processes, multivariate statistical approaches are required. Multivariate techniques are ideally suited to studies where multiple response variables are measured in the same observational or experimental study; they have been used extensively for terrestrial ecological studies and fisheries studies, e.g. Beaugrand and Reid (2012). These analyses are used to test complex hypotheses about regional differences and relationships between variables (Havenhand et al., 2010). Used in this way, observational data can inform us of ocean change impacts and complement more targeted and more finelydetailed experimental research (Collins et al., 2014; Sunday et al., 2014). Some earlier field studies have also analyzed linkages between carbonate chemistry and species composition in an OA context using multivariate statistics (e.g. Charalampopoulou et al. (2011); Charalampopoulou et al. (2016)). Frigstad et al. (2013) reported the need for comprehensive studies on all available environmental data (with lots of variables) to determine causal relationships.

The main goal of this paper is to investigate quantitatively the links between natural spatial variations in environmental factors and: i) plankton biodiversity and community 
structure, ii) climatically-active gases and, iii) biogeochemical variables, across the highly dynamic environment of the northwest European Shelf waters. Trying to identify which combination of environmental variables drives biogeochemical variables is difficult due to the complexity of responses, interactions, and spatial variability. Here, we used a multivariate statistical approach to address this problem and identify statistically the strongest combinations of environmental variables associated with the response variables. In doing so, we were able to determine which response variables were most influenced by changes in sea surface carbonate chemistry gradients. As such, this study represents a large and comprehensive addition to the literature on OA impacts on the surface ocean, as deduced from observational data.

\section{Methods}

Samples were collected between June- July 2011 during the RRS Discovery research cruise (D366) in northwest European Shelf waters (Fig. 1), as part of the UK ocean acidification (UKOA) research programme. The data reported in this study came from multiple measurements collected within the mixed layer. Several previous papers describing results of experimental and observational work on this cruise have been published in a 2014 special issue (Tyrrell and Achterberg, 2014). Here we present an overarching statistical analysis of the observational data. Across the cruise more than 20 environmental variables (physical, nutrients and carbonate chemistry), $>120$ plankton species abundance measurements and 22 other response variables (biogeochemical variables and climaticallyactive gases) were collected at 64 stations (some of them were visited twice) (Fig. 1). All data included in the paper are available from the British Oceanographic Data Centre (Ribas-Ribas et al., 2014a). 


\subsection{Environmental data}

Temperature and salinity were taken directly from the calibrated CTD data. Analyses of nitrate and nitrite $\left(\mathrm{NO}_{\mathrm{x}}\right)$, phosphate $\left(\mathrm{PO}_{4}\right)$, and silicic acid $\left(\mathrm{Si}(\mathrm{OH})_{4}\right)$ were undertaken using a segmented flow auto-analyser (Skalar San+) following methods described by Kirkwood (1989). Excess nitrate relative to phosphate $\left(\mathrm{N}^{*}\right)$ was calculated as $\mathrm{NO}_{3}-\left(\mathrm{PO}_{4} \mathrm{x} 16\right)$ and excess silicic acid relative to nitrate $\left(\mathrm{Si}^{*}\right)$ was calculated as $\mathrm{Si}(\mathrm{OH})_{4}-\mathrm{NO}_{\mathrm{x}}$ (Poulton et al., 2014). Analysis of high quality seawater carbonate chemistry measurements are detailed in Ribas-Ribas et al. (2014b).

Mixed layer depths (MLD) were calculated as the shallowest depth at which the density difference $\left(\Delta \sigma_{t}\right)$ with the surface waters was more than $\Delta \sigma_{t}=0.05 \mathrm{~kg} \mathrm{~m}^{-3}$. This threshold has been previously used on the eastern European continental shelf (Hickman et al., 2012). Daily incident irradiance $\left(\mathrm{Ed}^{0-}\right)$, in terms of photosynthetically active radiation (PAR), was integrated from dawn to dusk from the PAR sensor on the RSS Discovery. The euphotic zone depth (Zeup) was defined as the depth at which irradiance was $1 \%$ of near-surface values, with an optical depth of 4.6 (Kirk, 1994). $K_{d}$ was calculated for pre-dawn casts using the same method as Charalampopoulou et al. (2011); regression analysis between turbidity (measured using a turbidity sensor on the CTD frame) and $K_{d}\left(\mathrm{r}^{2}=0.493 ; \mathrm{p}<0.001\right)$ values calculated for daytime stations were used to predict $K_{d}$ for pre-dawn casts. The mixed layer average irradiance $\left(\mathrm{Ed}^{\mathrm{ML}}\right)$ was calculated following Kirk (1994) using a combination of $\mathrm{Ed}^{0-}$, $\mathrm{K}_{\mathrm{d}}$, and MLD as in Equation 1:

$\operatorname{Ed}^{\mathrm{ML}}\left(\operatorname{mol}\right.$ PAR m$\left.{ }^{-2} \mathrm{~d}^{-1}\right)=\operatorname{Ed}^{0-}\left(1-\exp ^{-\mathrm{Kz}}\right) / \mathrm{K}_{\mathrm{z}}$ (Eq. 1)

where $\mathrm{K}_{\mathrm{z}}=K_{d} \cdot \mathrm{MLD}$. The variable $\mathrm{Ed}^{\mathrm{ML}}$ describes the mean light experienced by a particle being mixed from the surface to the base of the mixed layer. A two day average was used as 
this accounts for incidental light and recent light history. This is especially important for morning measurements, where light data from the sampling day is most representative of the time after sampling.

In all, 19 environmental variables were measured at the same stations where the phytoplankton variables were measured (Table 1). Prior to statistical analysis, multicollinearity of the environmental variables within each environmental group (nutrients, carbonate chemistry, and hydrographical variables) and overall (all groups combined) were determined using Pearson's product moment correlations. For pairs of collinear variables ( $\rho>0.95$; e.g. dissolved inorganic carbon/total alkalinity $\left.\left(\mathrm{DIC} / A_{\mathrm{T}}\right)\right)$, we checked the analysis with both variables to examine if they both produced the same statistical outcome and then, if they did, one of the variables was removed from the subsequent analysis.

If the explanatory variables had a skewed distribution they were transformed appropriately (Quinn and Keough, 2002). All variables were normalized (subtracting the mean and dividing by the standard deviation for each variable) prior to being constructed into a resemblance matrix using Euclidean distance (Equation 2):

$D=\sqrt{\sum_{i}\left(y_{i 1}-y_{i 2}\right)^{2}}$

where $y_{i 1}$ and $y_{i 2}$ result from the pre-treatment transformation and subsequent normalisation.

\subsection{Phytoplankton data}

Methods for coccolithophore counts are detailed in Poulton et al. (2014). After filtering and mounting as permanent slides, coccolithophore cell counts and species identification were carried out under cross-polarised light using a Leitz Ortholux microscope (X1000, oil immersion). 
Microplankton community samples collected from the CTD casts were preserved in $2 \%$ acidic Lugol's iodine solution and stored in cool, low light conditions. The Utermöhl method for quantitative phytoplankton analysis (Edler and Elbrächter, 2010) was used for taxonomic identification and quantitative analysis of microplankton greater in cell size than $10 \mu \mathrm{m}$.

Spatial variation in the plankton community was assessed individually for each phytoplankton group (diatoms, dinoflagellates, and coccolithophores), as well as for all groups combined (with and, in some cases, without unidentified naked dinoflagellates). Abundance data for all groups were aggregated to the genus level, and screened to keep taxa that appeared in $\geq 1 \%$ of the samples; in each of the plankton groups, taxa were $\log$ transformed $(\log [\mathrm{X}+1])$ to down-weight the contributions of the dominant species prior to being constructed into a similarity matrix using the Bray-Curtis similarity coefficient (Equation 3):

$S_{j k}=100\left\{1-\frac{\sum_{i=1}^{p} y_{i j}-y_{i k}}{\sum_{i=1}^{p}\left(y_{i j}+y_{i k}\right)}\right\}$

where $y_{i j}$ represents the entry in the $i$ th row and $j$ th column of the data matrix for the $i$ th species in the $j$ th sample and $y_{i k}$ is the count for the $i$ th species in the $k$ th sample.

To assess if the calcifying plankton group contributed less to the total phytoplankton community in regions of low $\mathrm{pH} /$ calcite saturation state $\left(\Omega_{\text {calcite }}\right)$, the total phytoplankton abundance data was sub-divided into calcifying and non-calcifying species. Diversity indices (total number of individuals $[\mathrm{N}]$, total number of species [S], and species richness [H', the Shannon-Wiener Index]) of (i) calcifying and (ii) non-calcifying groups were determined, as well as the (iii) ratio of diversity indices between calcifying:non-calcifying groups. The Shannon-Wiener Index was determined by (Equation 4):

$H^{\prime}=\sum\left(P_{i} \cdot \log \left(P_{i}\right)\right)$ 
where $P_{i}$ is the proportion of the total count arising from the $i$ th species.

\subsection{Response variable data}

Methods used for the analysis of DMS, DMSP, $\mathrm{N}_{2} \mathrm{O}$, methane $\left(\mathrm{CH}_{4}\right), \mathrm{POC}$, particulate organic nitrogen (PON), particulate organic phosphorus (POP), TEP, chlorophyll- $a$ (Chl-a) biogenic silica (BSi), and dissolved oxygen (DO), can be found in Richier et al. (2014) and references therein (see Table 3 in Richier et al. (2014)). Herein, C:N, C:P, N:P are the ratios of POC:PON, POC:POP, and PON:POP, respectively.

\subsection{Statistical analysis}

Phytoplankton community assemblages sampled across the northwestern European Shelf were analysed using multivariate approaches with PRIMER-E v6 (6.1.13) and PERMANOVA + (1.0.3). Table 2 summarizes the statistical analyses used in this study.

\subsubsection{Principal components analysis}

A principal component analysis (PCA) was used to visually represent the variation across all the environmental forcing variables (physical, carbonate chemistry, and nutrients) and to assess if natural groupings found within the data were similar to those found in the phytoplankton community assemblage.

\subsubsection{Cluster analysis}

Natural groupings in the environmental data were differentiated using cluster analysis of the group average and statistically compared using similarity profile ('SIMPROF') analysis. Similarity percentages ('SIMPER') analysis were then used to determine which 
variables are characteristic of each environmental cluster, variables which cumulatively contribute least to $50 \%$ of Euclidean distance (and are therefore most 'similar') between stations grouped in a cluster; as well as discriminating variables which contribute the most toward $50 \%$ of total Euclidean distance between pairs of clusters.

\subsubsection{Principal co-ordination analysis}

To visualise the natural groupings of the phytoplankton community, a principle coordination analysis (PCO) was employed. PCO is an unconstrained plot where samples are projected onto a best fitting plane, by which the axes aim to capture as much variability from the (Bray Curtis or Euclidian distance) resemblance matrix as possible.

\subsubsection{Analysis of similarities}

Analysis of similarities (ANOSIM) was carried out to determine whether the phytoplankton assemblages varied between a priori specified groups of stations that are characterized by differing environmental characteristics, determined independent of the phytoplankton analysis.

The global value of $\mathrm{R}$ varies between 1 and -1 ; values greater than 0 indicate greater variation between groups than within group, where 1 would indicate all stations within a group are more similar to each other than to any station from another group. Global $\mathrm{R}$ and associated significance values were used initially to determine whether significant differences were present $(p<0.05)$; pairwise comparisons were investigated further for combinations with lower $\mathrm{p}$ values $(\leq 0.1)$ and higher R statistics $(\geq 0.4)$ (Clark et al., 2014). Subsequent SIMPER analysis was then used to examine the discriminating species (those contributing to $50 \%$ of dissimilarities (Bray-Curtis) between clusters) in each pairwise comparison, which were then compared to the corresponding environmental variables.

\subsubsection{Mantel Test}


To assess if the spatial variations in plankton groups were related to carbonate chemistry gradients rather than other environmental factors, all three environmental forcing groups (nutrients, carbonate chemistry, and hydrographical variables) were separately, and in combination, correlated to the plankton groups using a non-parametric Mantel Test (RELATE analysis). The measure of agreement between the matrices was assessed with Spearman's rank correlation coefficient (rho) with permutations to test the null hypothesis of no agreement in the multivariate patterns between the two independently derived resemblance matrixes.

Significant correlations were analysed further using BEST analysis (BVstep, 999 permutations) to determine a subset of variables within the environmental group that best matched the biotic pattern in the phytoplankton group. BEST analysis performs a permutation-based multivariate analysis of biotic-abiotic relationships to link the patterns in the response variables to those in the environmental variables. The BEST analysis finds which subset of environmental variables produce the highest Spearman's rank correlation between a Bray-Curtis similarity matrix (responses) and Euclidean distance matrix (environmental). The permutation test indicates the probability of achieving this correlation by chance, therefore providing a significance test for the correlation.

To gauge if the community structure of the phytoplankton were related to carbonate chemistry gradients rather than other environmental factors, the analysis as described above was repeated but each CTD station was first standardised to the total number of individuals within each sample. A distance-based linear model (DISTLM) was used to model the relationship between the environmental forcing variable group (nutrients, carbonate chemistry, and hydrographical variables) and the phytoplankton abundance. Marginal tests were used to assess the (i) relative influence of each independent environmental variable, and (ii) each forcing variable group on the phytoplankton assemblage using $\mathrm{R}^{2}$ selection criteria. 
Sequential testing in a step-wise model was then used to assess the best subset of forcing variables (overall and within each environmental group) that can be used to model the variability within the phytoplankton community. The modified Akaike Information Criterion $\left(\mathrm{AIC}_{\mathrm{C}}\right)$ selection criterion was used for the step-wise model due to its capability of handling a small number of samples relative to the number of predictor variables available. The distance based linear model was repeated for the three sub-groups within the phytoplankton: coccolithophores, diatoms, and dinoflagellates.

RELATE analysis was also used to correlate the multivariate response of the diversity indices across the three environmental variable groups. As the diversity indices were measured on different scales, they were normalised prior to being constructed into a resemblance matrix using Euclidean distance. Significant correlations were analysed further for individual diversity indices using BEST analysis to isolate a sub-set of carbonate variables that best matched the biotic data.

\subsubsection{Multiple linear regression model (LM) and generalized linear model (GLM)}

Correlations between the independent explanatory/response variables (Table 1) and the response variables (climatically-active gases and biogeochemical variables) were analysed across the northwestern European Shelf using either Pearson's correlation coefficient $(\rho)$ or rho, dependant on the heterogeneity of the response variables. Significance $(p<0.05)$ of the correlations between the response variables and the independent explanatory variables was generated using permutations (9,999 permutations). The combination of forcing variables (carbonate chemistry, nutrient, and physical variables combined) that had the greatest influence on the response variables was assessed using step-wise multiple linear regressions. If the response variable maintained homogeneity of variance and a normal distribution, a multiple linear regression model (LM) was used. If the distribution of the response variable 
was skewed, a generalized linear model (GLM) was obtained. The significance of the coefficients within each of the models was analysed using either analysis of variance (for the LM) or the Wald Test (for the GLM), and significant differences from the null model were assessed using the F- statistic (for the LM) and the Chi-squared statistic (for the GLM). Prior to analysis, multicollinearity between the explanatory variables was assessed using Pearson's correlation. Variables with a correlation $>0.95$ were removed. Redundant variables (those that maintained a high collinearity with another variable) were substituted into the regression analysis in a stepwise fashion to assess their overall influence on the significance. Model inference and goodness of fit was assessed with AICc, and either residual deviance of variance using $\mathrm{R}^{2}$ (for $\mathrm{LM}$ ) or log-likelihood ratios (for GLM). Model validation was assessed by comparing the residual variance/ deviance against the fitted values. Spatial autocorrelation was visually assessed through variograms and all residuals were compared to explanatory variables and assessed for patterns.

\section{Results}

\subsection{Environmental forcing and response variables}

PCA grouped most environmental variables into either physical (more related to PC2Env) or carbonate chemistry and nutrients (PC1-Env). Response variables were mostly grouped into climatically active gases (PC1-Res) and biogeochemical variables (PC2-Res). The range of environmental variability encountered across the D366 cruise is detailed in Table 1 (see also Tyrrell and Achterberg (2014)). The PCA of all environmental variables combined captured $57.3 \%$ of the spatial variability across the first two principle components (Fig. 2A). The first principle component accounts for $33.8 \%$ of the variability within the data and correlated strongly (Pearson's correlation, $\rho>0.8$ or $\rho<-0.8$ ) to the $\mathrm{MLD}, \mathrm{Si}(\mathrm{OH})_{4}, f \mathrm{CO}_{2}$, and $\mathrm{HCO}_{3}{ }^{-}$and negatively with saturation states. The second principle component accounts 
for $23.5 \%$ of the variability within the data and correlated positively with salinity and $A_{\mathrm{T}}$ and negatively to temperature and $f \mathrm{CO}_{2}(\rho<-0.77)$. The PCA of response variables combined captures $48.2 \%$ of the spatial variability across the first two principle components (Fig. $2 \mathrm{~B}$ ). The first principle component correlated strongly with POC and PON and the second principle component correlated positively with POP and negatively with the ratio of C:P.

Cluster and subsequent SIMPROF analysis of environmental variables highlighted 12 significantly different clusters at the 5\% significance level (Fig. 3A). The clusters were then located geographically (Fig. 3B). This showed a large degree of heterogeneity in environmental variables; however, some of the environmental clusters were strongly geographically separate, allowing the identification of several important geographic regions: South of Cornwall (cluster 'l'), open Atlantic (cluster 'f' and 'g' (both together)), Skagerrak/Norwegian coast (cluster 'b'), or with coastal influence (cluster 'c' and 'e') which receive large freshwater inputs from the English, Belgian, Dutch, German, and Danish coasts.

\subsubsection{Climatically-active gases}

Analysis of correlations between the climatically-active gases and environmental forcing variables revealed that one or more carbonate chemistry variables significantly influenced DMS, DMSP, and $\mathrm{N}_{2} \mathrm{O}$ concentrations, but had no influence on $\mathrm{CH}_{4}$ (supplementary material, Fig. 1S). Multiple linear step-wise regression found temperature was the main forcing variable influencing the concentration of $\mathrm{N}_{2} \mathrm{O}$ across the northwestern European Shelf (supplementary material, Table 1S). For this climatically-active gas, an increase in temperature results in a decline in its concentration. Methane concentration was most influenced by MLD and $\mathrm{PO}_{4}$, with an increase in MLD associated with lower $\mathrm{CH}_{4}$ concentration, whilst an increase in $\mathrm{PO}_{4}$ increased $\mathrm{CH}_{4}$ concentration. DMS and DMSP concentration were influenced by the carbonate chemistry gradients in concert with other environmental variables. Salinity, Zeup, and $f \mathrm{CO}_{2}$ had the greatest influence on DMS 
concentration, with the increase in both salinity and $f \mathrm{CO}_{2}$ causing declines in DMS concentration, whilst Zeup increased concentration. Salinity, $\mathrm{N}^{*}, \mathrm{NO}_{3}, \mathrm{Si}(\mathrm{OH})_{4}$, Zeup, and $f \mathrm{CO}_{2}$ had the greatest influence on DMSP concentration, explaining $80 \%$ of the deviance within the data. Increases in salinity, $\mathrm{N}^{*}$, and $\mathrm{Si}(\mathrm{OH})_{4}$ positively influenced the concentration of DMSP, whilst $f \mathrm{CO}_{2}, \mathrm{NO}_{3}$, and Zeup had a negative association.

\subsubsection{Biogeochemical variables}

Correlations between environmental forcing variables and biogeochemical variables revealed that the carbonate chemistry gradients were only related to the elemental stoichiometry (C:N and C:P) (supplementary material, Fig. 2S). Multiple linear step-wise regressions found that the variables within the physical and nutrient forcing groups had a greater influence on the biogeochemical variables than did the carbonate chemistry variables (supplementary material, Table $1 \mathrm{~S}$ ). $\mathrm{N}^{*}$ and $\mathrm{Ed}^{\mathrm{ML}}$ had the greatest influence on POC, with both variables increasing its concentration. Zeup, MLD, seafloor depth, salinity, and Si* had the greatest influence on PON, while MLD and $\mathrm{HCO}_{3}{ }^{-}$had the greatest influence on POP. Elemental stoichiometry of $\mathrm{C}: \mathrm{N}$ was influenced by the combination of temperature, $\mathrm{HCO}_{3}{ }^{-}$, and $f \mathrm{CO}_{2}$. Increased temperature and $\mathrm{HCO}_{3}{ }^{-}$concentration increased the $\mathrm{C}: \mathrm{N}$ elemental stoichiometry, whilst increases in $f \mathrm{CO}_{2}$ decreased the ratio. C:P stoichiometry was influenced by $\mathrm{DIC}$ and $\mathrm{Si}^{*}$, with both variables declining the ratio with their increased concentration, and the $\mathrm{N}: \mathrm{P}$ ratio was most influenced by temperature, $\mathrm{N}^{*}$, and $\mathrm{Si}(\mathrm{OH})_{4}$.

POP, C:P, and $\mathrm{C}: \mathrm{N}$ were significantly influenced by $\mathrm{HCO}_{3}{ }^{-}, \mathrm{DIC}$, and $f \mathrm{CO}_{2}$. It was found that POC was strongly correlated with DIC. All biogeochemical variables except C:P were significantly influenced by hydrographic variables (mainly temperature, MLD, and salinity). Nutrients were significantly correlated to all biogeochemical variables except POP and C:N. In our study with natural variation, $\mathrm{C}: \mathrm{P}$ and $\mathrm{C}: \mathrm{N}$ are negatively correlated with carbonate chemistry whereas $\mathrm{N}: \mathrm{P}$ showed no influence of any carbonate chemistry variable. 
Independently, one or more of the carbonate chemistry variables influenced the concentrations of TEP, chlorophyll- $a$, and dissolved oxygen (DO) (supplementary material, Fig. 3S). Multiple linear step-wise regressions found the combination of seafloor depth, salinity, $\mathrm{N}^{*}$ and DIC had the greatest effect on TEP concentration, with DIC having a negative association with TEP concentration (supplementary material, Table 1S). The combination of $\mathrm{Ed}^{\mathrm{ML}}$, temperature, salinity and $f \mathrm{CO}_{2}$ had the greatest influence on the concentration of DO. An increase in $f \mathrm{CO}_{2}$, temperature and salinity concentrations resulted in a decrease in concentration of $\mathrm{DO}$, whilst $\mathrm{Ed}^{\mathrm{ML}}$ had a positive influence on its concentration. Temperature, Zeup, $\mathrm{NO}_{3}, \mathrm{DIC}, A_{\mathrm{T}}$ and $f \mathrm{CO}_{2}$ had the greatest influence on chlorophyll- $a$, all together accounting for $68 \%$ of the deviance within the data. For biogenic silica, Zeup, seafloor depth, temperature and $\mathrm{Si}(\mathrm{OH})_{4}$ had the greatest influence, together explaining $50 \%$ of the deviance within the data.

Saturation states of aragonite $\left(\Omega_{\text {aragonite }}\right)$ and calcite $\left(\Omega_{\text {calcite }}\right)$ are statistically different between regions (Fig. 4A). For example, the Irish Sea (clusters 'a' and 'i' in Fig. 3) had the lowest values and was statistically different from all of the other regions. The Skagerrak also had low $\Omega_{\text {calcite }}$ and $\Omega_{\text {aragonite }}$ values and was statistically different from all the other regions. Generally, the Atlantic sector was similar to the Celtic Sea. In the Bay of Biscay we found the highest values, statistically separate from the entire study region. The English Channel and Norwegian coast were not statistically distinct from one another. However, the phytoplankton community structure was not influenced by regions of low $\mathrm{pH} / \Omega_{\text {calcite. The multivariate }}$ response of the species diversity indices ( $\mathrm{S}, \mathrm{N}$, and $\left.\mathrm{H}^{\prime}\right)$ in calcifying groups, non-calcifying groups, and the ratio between calcifying: non-calcifying groups was not found to correlate to the carbonate chemistry gradients in the northwest European shelves (Fig. 4B).

\subsection{Phytoplankton community}


The phytoplankton community composition, either as a whole or segregated into separate taxonomic groups, did not correlate to the spatial patterns in carbonate chemistry gradients. However, the multivariate pattern of the phytoplankton community assemblage did correlate significantly to the variation in nutrient pools ( $r$ ho $=0.237, p=0.021$ ), and BEST analysis found that $\mathrm{PO}_{4}, \mathrm{~N}^{*}$, and $\mathrm{Si}^{*}$ had the greatest correlation to the phytoplankton community structure (rho $=0.268, p=0.039$ ). Only the diatom community composition was found to significantly correlate to the nutrient environmental forcing variables (rho $=0.304, p=0.001$ ), which BEST analysis matched to the concentrations of $\mathrm{NO}_{3}$ and $\mathrm{Si}(\mathrm{OH})_{4}($ rho $=0.333$, $p=0.001)$. Combining all environmental forcing variables together, $\mathrm{H}^{+}, \mathrm{Si}(\mathrm{OH})_{4}$, and $\mathrm{NO}_{3}$, were found to best explain the patterns in the multivariate diatom abundance data (rho $=$ $0.341, p=0.005)$

ANOSIM revealed no significant difference in the phytoplankton community composition $(\mathrm{R}=0.13, \mathrm{p}=0.085)$ between natural environmental clusters (see section 3.1, Fig. 3A). However, following the removal of unidentified naked dinoflagellates, ANOSIM did reveal some significant differences in the phytoplankton community composition $(\mathrm{R}=0.211, \mathrm{p}=0.014)$ between natural environmental clusters (Fig. 3A), driven by variation in a number of species including coccolithophores (E. huxleyi), dinoflagellates (Gymnodinium spp. and Noctiluca spp.), and diatoms (Rhizosolenia spp., Dactyliosolen spp., and Guinardia spp.). Interestingly, ANOSIM revealed no significant difference in the phytoplankton group totals $(\mathrm{R}=0.109, \mathrm{p}=0.113)$ between natural environmental clusters.

There were 9 natural groups found in the community structure of the phytoplankton data (graph not shown). These 9 groups were predominantly split on the basis of unidentified naked dinoflagellate community abundance. However, this group skewed the data due to it representing a large taxonomic clade, while all other groups were individual species aggregated to genus. Therefore additional analyses were made with naked dinoflagellates 
removed. Their removal resulted in 2 distinct groupings within the phytoplankton community (Fig. 5A), which were distinguished by the dominance of the dinoflagellate Gymnodinium spp. in Group A (contributing to $78 \%$ similarity between samples within this group) and the coccolithophore E. huxleyi in Group B (contributing to $61 \%$ similarity between samples within this group).

Coccolithophores formed 7 natural groupings within the community (Fig. 5B). The dominance of E. huxleyi caused the greatest differences between the groups, with E. huxleyi dominating $100 \%$ of the samples in group $\mathrm{F}$ and none of the samples in group A. Gephyrocapsa muellerae and Syracosphaera marginaporata were also discriminating species. E. huxleyi was an important discriminating species between many clusters, largely explained by high dominance in clusters 'b', 'j', and ' 1 ' and comparatively lower dominance in cluster 'g' (Fig. 3A). There is slight evidence of an association between increased E. huxleyi dominance and some carbonate chemistry variables, with decreased $A_{\mathrm{T}}$ and $\mathrm{CO}_{3}{ }^{2-}$ being discriminating variables in $40 \%$ and $20 \%$ of the pairwise comparisons, respectively. Physical parameter groupings were more strongly linked to E. huxleyi dominance, with shallower MLD and decreased salinity both being discriminating variables in $60 \%$ of comparisons each, associated with increased dominance. Increased E. huxleyi dominance was also linked to increased temperature and seafloor depth in a single comparison $(20 \%)$ each. Increased $E$. huxleyi dominance also showed relatively clear links to nutrients, with low phosphate also being a discriminating variable in $60 \%$ of pairwise comparisons, and lower nitrate in an additional comparison. Additionally, when analysing coccolithophores independently, $E$. huxleyi dominance was more closely linked to shallow MLD, high irradiance, and lower salinity (see also Poulton et al. (2014)).

Excluding the unidentified naked dinoflagellates, the dinoflagellate group formed 5 natural groupings within the community structure (Fig. 5C). Group A and B was dominated 
by Gymnodinium spp. (contributing to $78 \%$ similarity between samples within this group) and Noctiluca spp. (contributing to $72 \%$ similarity between samples within this group), respectively. A combination of Ceratium spp., Scrippsiella spp., Katodinium spp., and Gymnodinium spp. dominated the community structure of dinoflagellate group E (contributing to $73 \%$ similarity between samples within this group), whilst group C and D only had one CTD sample within their cluster. ANOSIM revealed no significant difference in the dinoflagellate community composition $(\mathrm{R}=0.012, \mathrm{p}=0.415)$ between natural environmental clusters determined in the cluster analysis (Fig. 3A). However, following removal of the unidentified naked dinoflagellates, there is evidence of a relationship between the dinoflagellate community composition and environmental variables: ANOSIM revealed some significant differences in the dinoflagellate (excluding unidentified naked dinoflagellates) community composition $(\mathrm{R}=0.188, \mathrm{p}=0.02)$ between natural environmental clusters (Fig. 3A).

In both the ANOSIM and conceptual model analyses, dinoflagellate assemblage composition was most closely linked to carbonate chemistry and the physical variables. These explained 20 and $21 \%$, respectively, of variability in the dinoflagellate assemblage composition, with $\mathrm{DIC} / \mathrm{HCO}_{3}^{-}$being the best overall subset of variables involved.

Diatoms formed 4 natural groupings within the community structure data (Fig. 5D). Group A had only one sample, which was segregated from the other significant clusters due to the dominance of Corethron spp. within this CTD sample. For instance, Corethron had high dominance (42\%) in cluster ' $h$ ' but was very low/absent in 'b', 'j', and ' 1 '. Groups B, C, and D were dominated by Rhizosolenia spp., Guinardia spp., and Coscinodiscus spp., respectively. When analysing diatoms independently, ANOSIM revealed significant differences in the diatom community composition $(\mathrm{R}=0.226, \mathrm{p}=0.009)$ between natural environmental clusters (Section 3.1, Fig. 3A). We identify Rhizosolenia spp. as a key diatom 
species, responsible for separating several different clusters either due to its high dominance $(\sim 65 \%)$ in cluster 'b' or its low dominance $(<5 \%)$ in ' $h$ ', 'c', and 'g' (Fig. 3A). The species that contribute to group separation were further investigated in section 4.2 to help identify which environmental parameters were behind these distributions.

We summarize how the variance in phytoplankton community composition in the northwest European Shelf in summer 2011 related to forcing factors in Fig. 6. All environmental forcing variables combined accounted for $59 \%$ of the variation within the phytoplankton community (Fig. 6A). The best overall subset of variables to predict the variation in the phytoplankton were $\mathrm{Si}(\mathrm{OH})_{4}$ and $\mathrm{N}^{*}$, which together account for $15 \%$ of the variation. The nutrient group explained the greatest proportion of variance within the phytoplankton abundance when the environmental variables were subdivided into groups. The combination of all environmental forcing variables accounted for 41,62 , and $58 \%$ of the variability within the separate plankton groups for coccolithophore, diatom, and dinoflagellate community structure, respectively (Fig. 6B-D). The best subset of variables to describe the variation in the diatom community assemblage were $\mathrm{NO}_{3}, \mathrm{Si}(\mathrm{OH})_{4}$, and $\mathrm{CO}_{3}{ }^{2-}$, which together accounted for $24 \%$ of the variation (Fig. 6D).

\section{Discussion}

We conducted a very large measurement campaign across a heterogeneous region within which environmental conditions varied considerably. We then undertook a rigorous statistical analysis of the data. Looking over the entirety of our results, it is apparent that while many potential response variables were apparently unrelated to carbonate chemistry, others were related to carbonate chemistry. For those response variables that correlated with carbonate chemistry, OA may well affect them. Where no correlations were found, it does not necessarily mean that those response variables will not be affected at all by OA. Other 
possible causes of a lack of correlation include: i) OA impacts exist but are too small to have been detected by our approach, ii) OA will impact the variables, but not within the range of carbonate chemistry encountered during our cruise, iii) OA will impact these response variables, but not under the specific environmental conditions encountered during our cruise (for instance only at higher temperatures than are found around the British Isles), and iv) OA will impact these response variables, but only when a different set of biological species are present (for instance only when the phytoplankton assemblage is dominated by picophytoplankton, as did not on our cruise). The evidence we compiled and analysed does not support a strong impact of OA on most variables but conversely does not rule it out.

We did not find any saturation state values as low (0.8) as in the US Pacific Northwest coast (Feely et al., 2008), where the oyster hatcheries are reported to be failing (Cooley and Doney, 2009; Dickson, 2010). However, the carbonate chemistry of the surface ocean is rapidly changing with OA. When interpreting the results of our analyses, it is important to be aware of the range of carbonate chemistry variation we measured on our cruise. For instance, during our cruise we sampled surface waters that varied in $f \mathrm{CO}_{2}$ between 264 and $411 \mu \mathrm{atm}$, in $\mathrm{pH}$ between 8.03 and 8.20, and in aragonite saturation state between 2.1 and 3.0 (RibasRibas et al., 2014b). The northwest European Shelf seas in summer could become undersaturated in aragonite $(<1)$ with a $f \mathrm{CO}_{2}$ in equilibrium with an atmosphere of $1150 \mu \mathrm{atm}$ (considering alkalinity constant and equal to an absorption of anthropogenic $\mathrm{CO}_{2}$ of $180 \mu \mathrm{mol}$ $\left.\mathrm{kg}^{-1}\right)$. In winter, taking into account the lowest temperature reported by Bozec et al. (2006) of $5.1^{\circ} \mathrm{C}$ the under-saturation would be reached at $750 \mu$ atm, which is less than double of actual levels. In terms of the general progression of OA, it will take $84 \pm 24$ years for the $f \mathrm{CO}_{2}$ of surface seawater to increase by $147 \mu \mathrm{atm}$ (the range of variation on our cruise), according to the average rate of increase measured at the major time-series sites in the global ocean (Bates et al., 2014). Likewise, the ranges of variability we encountered in $\mathrm{pH}$ and $\Omega_{\text {aragonite }}$ 
correspond to $98 \pm 25$ and $106 \pm 19$ years respectively of OA impacts at current rates according to the time-series measurements (Bates et al., 2014). These considerations lead to some limitations in the likely applicability of our results, if they turn out not to apply outside the range of environmental variability from which they were derived. For instance, for the study region around the British Isles, if OA continues at current rates then by the year 2142 (125 years from now) the carbonate chemistry of the whole region will no longer overlap at all with the range of environmental variation that we experienced and the inferences from our analyses might then no longer apply.

We demonstrate that observational data can inform us on ocean change impacts and complements experimental research. It is vital to systematically link responses seen in laboratory studies to changes seen in natural populations so that we can detect and understand changes to marine phytoplankton in changing oceans (Collins et al., 2014). Experimental research has certain shortcomings: i) a general inability to address the possibility of adaptation to the imposed change (Sunday et al., 2014); ii) a tendency to simplify both the abiotic and biotic features of the natural environment (Collins et al., 2014), for example, many laboratory studies change only a single environmental factor (usually $f \mathrm{CO}_{2}$ ), whereas numerous simultaneous environmental changes occur naturally; iii) ignorance of the recent life history of phytoplankton population, which will affect the strength and effectiveness of natural selection (Collins et al., 2014). For example, species in environments historically exposed to unpredictable changes of $f \mathrm{CO}_{2}$ might have greater adaptability than those in a more predictable $f \mathrm{CO}_{2}$ regime (Sunday et al., 2014).

\subsection{Climatically-active gases and biogeochemical variables}

$\mathrm{CH}_{4}$ and $\mathrm{N}_{2} \mathrm{O}$ were not found to be significantly correlated with carbonate chemistry, whereas DMS and DMSP were statistically influenced by $f \mathrm{CO}_{2}$. A consistent increase in DMS 
and decrease in DMSP in response to high $\mathrm{CO}_{2}$ was observed in mesocosm studies during the same cruise (Hopkins and Archer, 2014). However, other studies have observed a decrease in DMS under high $\mathrm{CO}_{2}$ concentrations (Hopkins et al., 2010) or no effect on concentration of DMSP in elevated $\mathrm{CO}_{2}$ (Lee et al., 2009). We observed in these variables a strong agreement between observational data and results of bioassay experiments conducted on the same cruise, but more studies are needed to fully elucidate the response of DMS/DMSP to increased $\mathrm{CO}_{2}$. Hydrographic variables and nutrients had significant effects on all the climatically-active gases studied. Clark et al. (2014) found a loose association between $\mathrm{N}_{2} \mathrm{O}$ and temperature at the stations where they measured $\mathrm{N}_{2} \mathrm{O}$ production rates. In contrast, we found a strong statistical association; maybe because of the higher range of variability and greater number of stations (all CTD stations) included in our analysis. This association between higher $\mathrm{N}_{2} \mathrm{O}$ concentration and lower temperature is most likely caused by increased gas solubility (Clark et al., 2014).

DIC and $f \mathrm{CO}_{2}$ explained a significant amount of variation in TEP, chlorophyll- $a$, and dissolved oxygen (DO), but not in biogenic silica. Hydrography and nutrients are important variables in explaining the biogeochemical variables. Several studies have examined the relationship between TEP and $f \mathrm{CO}_{2}$ in experimental manipulation studies (Engel, 2002; MacGilchrist et al., 2014) or model studies (Schneider et al., 2004); all of them concluded that rising $\mathrm{CO}_{2}$ will enhance TEP concentration and therefore that TEP would be expected to positively correlate with DIC. Our findings contradict those of manipulation studies, with TEP negatively correlated with DIC ( $p$-value $<0.001$ ). How the experiments were acidified may have influenced their results, because $A_{\mathrm{T}}$ and not DIC or $\mathrm{pH}$ are responsible for the changes (Passow, 2012). However, multiple linear regression in natural conditions highlight DIC and not $A_{\mathrm{T}}$ as a main factor of change (supplementary material). Notably, Richier et al. (2014) also found that net production of POC was strongly correlated with net changes in DIC. 
Dissolved oxygen appeared to be influenced by carbonate chemistry when in conjunction with other forcing variables; DO was seen to have lower values under elevated $f \mathrm{CO}_{2}$. Dissolved oxygen and chlorophyll- $a$ are the linking point of our two separate analyses of phytoplankton and response variables, reflecting the complexity, variability, and co-variation of the system. Thus, for example, our observations related DO with temperature, light, and $f \mathrm{CO}_{2}$ but clearly temperature affects DO concentration via solubility. Equally, chlorophyll- $a$ is also influenced by light availability, while the light environment will also be affected by chlorophyll- $a$ in terms of its attenuation in the water column.

\subsection{Phytoplankton community}

In combining all parts of the analysis, it is apparent that the spatial variation in total phytoplankton community was most closely linked to the variation in physical and nutrient variables, rather than carbonate chemistry during summer 2011.

Throughout most of the region, E. huxleyi characterized the phytoplankton community, with only a few stations, including a number of those in the Celtic Sea, lacking this species (see also Poulton et al. (2014)). Both in relation to the phytoplankton community as a whole and within the coccolithophore community, the relative dominance of E. huxleyi was largely linked to physical variables; MLD, Ed ${ }^{\mathrm{ML}}$, salinity, and Zeup, as well as the nutrient variables; particularly $\mathrm{PO}_{4}$ concentrations and the relative availability of nitrate to phosphate $\left(\mathrm{N}^{*}\right)$. These patterns are in general agreement with much of the literature: coccolithophore blooms are often promoted by the onset of surface stratification, associated with high irradiance and temperatures (Tyrrell and Merico, 2004). $\mathrm{Ed}^{\mathrm{ML}}$ and $\mathrm{pH}$ explained much of the variation in coccolithophore distribution and community composition in a study from the North Sea to the Norwegian Sea (Charalampopoulou et al., 2011). We hypothesise that this is because E. huxleyi is more tolerant of high light irradiances compared to other 
species; however, there is scant laboratory data to fully explore this. Adaptations to high light irradiances are thought to be an important factor supporting coccolithophore dominance in highly stratified surface waters during summer (Nanninga and Tyrrell, 1996). Studies on $E$. huxleyi have indicated that light saturation occurs at much higher irradiances, and that there has been no evidence of photo-inhibition, even at very high irradiances which have inhibitory effects on other phytoplankton groups (Rost and Riebesell, 2004).

While this was clear when analysing coccolithophores independently, links between irradiance and E. huxleyi dominance within the total phytoplankton community were less clear. In one of the comparisons, increased dominance is seen in the Skagerrak (cluster ' $b$ ') associated with lower $\mathrm{Ed}^{\mathrm{ML}}$ and phosphate, and higher temperature and seafloor depth. However, we note that the Skagerrak and Norwegian coast also had a shallow MLD and that incident irradiance here was particularly low. This observation could have been due to the persistence of E. huxleyi cells grown prior to measurements, when incident irradiance and consequently $\mathrm{Ed}^{\mathrm{ML}}$ may have been greater.

Young et al. (2014) examined coccoliths from the same cruise on the northeast European Shelf and concluded that the main differences between coccolithophore assemblages were between oceanic and neritic communities, i.e. whether the environmental location was on the shelf or in deep water. This was not entirely reflected in our analysis of the coccolithophore community, with increased seafloor depth also linked to higher E. huxleyi dominance. However this observation was largely due to the very high dominance in the Skagerrak region, which featured an extremely shallow and warm surface mixed layer, yet deep seafloor depth. Other regions with notably high E. huxleyi dominance were typically shelf waters while a more mixed assemblage was found offshore (Poulton et al., 2014). Semienclosed shelf waters typically had greater riverine input leading to lower salinities, which would also strengthen the stratification of the water column, as seen in the Skagerrak. 
Some of the dinoflagellates in the acidic Lugol's samples were likely to be heterotrophic, especially the small $(<20 \mu \mathrm{m})$ unidentified ones. The photoautotrophic dinoflagellates require $\mathrm{CO}_{2}$ for carbon fixation. However, the concentration of dissolved $\mathrm{CO}_{2}$ in seawater is relatively low and hence autotrophs require it to be concentrated within the cell via carbon concentrating mechanisms (CCMs). These CCMs vary widely among taxa, with a range of mechanisms and efficiencies (Giordano et al., 2005). Consequently, increases in $f \mathrm{CO}_{2}$ may be beneficial to some phytoplankton, though the extent of this will differ according to methods of carbon acquisition (Riebesell and Tortell, 2011). This could provide some explanation for the observed links between carbonate chemistry and the species composition of both diatom and dinoflagellate assemblages. Most phytoplankton have highly efficient CCMs and are typically not $\mathrm{CO}_{2}$ limited at current $f \mathrm{CO}_{2}$ (Doney et al., 2009), but those with less efficient $\mathrm{CCMs}$, or that rely on passive diffusion of $\mathrm{CO}_{2}$, are likely to benefit from increases in $\mathrm{CO}_{2}$. Alternatively, elevated $\mathrm{CO}_{2}$ concentration could reduce the energy required for CCMs, which in turn, could be allocated to other cellular processes (Riebesell and Tortell, 2011). Additionally, phytoplankton regulate cellular $\mathrm{pH}$ levels, and the ability to cope with increased concentration of $\mathrm{H}^{+}$has generally been shown to scale with size; large $(>50 \mu \mathrm{m})$ celled phytoplankton experience greater natural variation in $\mathrm{H}^{+}$concentration and are consequently better adapted to this (Richier et al., 2014). Different sizes of phytoplankton could explain some species specific responses: small phytoplankton $(<50 \mu \mathrm{m})$ are more greatly affected by proton concentration fluctuations due to bigger surface area to volume ratios than larger phytoplankton (Richier et al., 2014).

The typical temporal patterns in diatom community structure in the North Atlantic Ocean and northwest European Shelf seas have been well documented (Lange et al., 1992; Leterme et al., 2005); strong and clear links can be seen between nutrients and physical structure of the water column and diatom dominance in features such as the spring bloom. It could be 
expected that similar links would be observed spatially. Dissolved nutrient concentrations, particularly silicic acid, and their relative proportions $\left(\mathrm{Si}^{*}\right)$ were found to be important variables to explain variation in the total phytoplankton, both in the BEST analysis and in the conceptual model. This could be indicative of the influence of diatoms on the total community; these are the only group which have a requirement for silicic acid, and where present diatoms can be strong competitors for nutrients (Egge and Aksnes, 1992). Though no single diatoms species was a major feature (such as E. huxleyi or Gymnodinium spp.), as a whole diatoms were a modest proportion of the community and could potentially influence overall community dynamics.

Physical and nutrient variables also had a strong influence on the species structure of the diatom assemblage. Diatom size, nutrient requirement, and nutrient acquisition vary widely amongst different species. High dominance was largely associated with more acidic conditions and a shallower, warmer, and nutrient depleted mixed layer. Rhizosolenia spp. regularly occur during the later stages of diatom blooms and are able to persist well into summer stratified and nutrient depleted conditions (Villareal, 1987). Meanwhile some species had greater dominance in conditions more typically associated with diatom blooms, such as a deeper, cooler, and more nutrient rich mixed layer.

Interestingly, each of the analyses pointed to some link between diatoms and carbonate chemistry and the ANOSIM analysis indicated potential species-specific responses to carbonate chemistry conditions. Rhizosolenia spp. were seen to cope well with more acidic conditions, which reflects some previous studies (Sommer et al., 2015). In contrast, Corethron spp. were typically found in less acidic environments. This could reflect the past productivity of the environment: low $\mathrm{pH}$ will indicate bloom and high abundances in some areas whereas high $\mathrm{pH}$ will be indicative of post-bloom and low abundances in other areas. 


\section{Conclusions}

We used observational data from a cruise to investigate controls on the spatial patterns of phytoplankton species and other response variables. When considering all of our results together, the spatial variations in total phytoplankton assemblage were found to be more strongly associated with variations in nutrient and/or physical variables than with carbonate chemistry gradients. The plankton community abundance, contribution of calcifying organisms, and composition did not change greatly between higher $\Omega_{\text {calcite }}$ and lower $\Omega_{\text {calcite }}$ conditions. However, carbonate chemistry, alongside physical and nutrient variables, is calculated to play a more prominent role in determining dinoflagellate and diatom assemblage compositions.

Climatically-active gases and biogeochemical variables showed some influence of carbonate chemistry variables; however nutrients and hydrography appear to be more important in explaining their spatial variations.

We report results for boreal summer when phytoplankton communities were dominated by dinoflagellates (Poulton et al., 2014), with the coccolithophore community dominated by E. huxleyi, whilst diatoms were in low abundances. Future studies should focus on seasonal variability when the phytoplankton community changes and temperature and other environmental variables will play an important role in producing variations in saturation states. Although we did not observe saturation states low enough that they could affect calcifying organism, caution should be taken as winter studies or regions affected by upwelling could experience much lower saturation states.

At this stage of OA research, it is essential to carry out micro/mesocosm studies alongside observational studies and to use multivariate statistics to understand the complex interactions within the data. 


\section{Acknowledgements}

This work is a contribution to the UK ocean acidification Research Programme (UKOA) which was jointly funded by the Department for Environment, Food, and Rural Affairs (Defra), the Natural Environment Research Council (NERC), and the Department of Energy and Climate Change (DECC) under grant agreements no. NE/H017348/1 and NE/H017097/1. MRR was supported by the European Research Council (ERC) project PASSME [grant number GA336408]. We thank the captain and the crew of RRS Discovery for assistance during the cruise. We thank Graeme MacGilchrist for his help with normality tests. We also thank S. Richier, D.C.E. Bakker, S. Archer, D. Clark, F. E. Hopkins, C. M. Moore, H. E. Lawson, E. P. Achterberg, G. A. Lee, M. Palmer, T. Shi, M. Stinchcombe, D. Suggett, J. Young, and all other cruise participants for contributing data for statistical analysis.

\section{References}

Bach, L. T., Riebesell, U., Gutowska, M. A., Federwisch, L., and Schulz, K. G. 2015. A unifying concept of coccolithophore sensitivity to changing carbonate chemistry embedded in an ecological framework. Progress in Oceanography, 135: 125-138.

Bates, N., Astor, Y., Church, M., Currie, K., Dore, J., González-Dávila, M., Lorenzoni, L., et al. 2014. A time-series view of changing ocean chemistry due to ocean uptake of anthropogenic $\mathrm{CO}_{2}$ and ocean acidification. Oceanography, 27: 126-141.

Beaugrand, G., and Reid, P. C. 2012. Relationships between North Atlantic salmon, plankton, and hydroclimatic change in the Northeast Atlantic. ICES Journal of Marine Science: Journal du Conseil, 69: 1549-1562. 
Bozec, Y., Thomas, H., Schiettecatte, L.-S., Borges, A. V., Elkalay, K., and de Baar, H. J. 2006. Assessment of the processes controlling seasonal variations of dissolved inorganic carbon in the North Sea. Limnology and Oceanography, 51: 2746-2762.

Callaway, R., Shinn, A. P., Grenfell, S. E., Bron, J. E., Burnell, G., Cook, E. J., Crumlish, M., et al. 2012. Review of climate change impacts on marine aquaculture in the UK and Ireland. Aquatic Conservation: Marine and Freshwater Ecosystems, 22: 389-421.

Charalampopoulou, A., Poulton, A. J., Bakker, D. C. E., Lucas, M. I., Stinchcombe, M. C., and Tyrrell, T. 2016. Environmental drivers of coccolithophore abundance and calcification across Drake Passage (Southern Ocean). Biogeosciences, 13: 5917-5935.

Charalampopoulou, A., Poulton, A. J., Tyrrell, T., and Lucas, M. I. 2011. Irradiance and pH affect coccolithophore community composition on a transect between the North Sea and the Arctic Ocean. Marine Ecology Progress Series, 431: 25-43.

Clark, D. R., Brown, I. J., Rees, A. P., Somerfield, P. J., and Miller, P. I. 2014. The influence of ocean acidification on nitrogen regeneration and nitrous oxide production in the northwest European shelf sea. Biogeosciences, 11: 4985-5005.

Collins, S., Rost, B., and Rynearson, T. A. 2014. Evolutionary potential of marine phytoplankton under ocean acidification. Evolutionary Applications, 7: 140-155.

Cooley, S. R., and Doney, S. C. 2009. Anticipating ocean acidification's economic consequences for commercial fisheries. Environmental Research Letters, 4: 024007.

Dickson, A. 2010. Ocean Acidification Impacts on Shellfish Workshop: Findings and Recommendations.

Doney, S. C., Fabry, V. J., Feely, R. A., and Kleypas, J. A. 2009. Ocean acidification: the other $\mathrm{CO}_{2}$ problem. Annual Review of Marine Science, 1: 169-192.

Edler, L., and Elbrächter, M. 2010. The Utermöhl method for quantitative phytoplankton analysis. Microscopic and molecular methods for quantitative phytoplankton analysis, 110. 
Egge, J., and Aksnes, D. 1992. Silicate as regulating nutrient in phytoplankton competition. Marine ecology progress series. Oldendorf, 83: 281-289.

Engel, A. 2002. Direct relationship between $\mathrm{CO}_{2}$ uptake and transparent exopolymer particles production in natural phytoplankton. Journal of Plankton Research, 24: 49-53.

Engel, A., Zondervan, I., Aerts, K., Beaufort, L., Benthien, A., Chou, L., Delille, B., et al. 2005. Testing the direct effect of $\mathrm{CO}_{2}$ concentration on a bloom of the coccolithophorid Emiliania huxleyi in mesocosm experiments. Limnology and Oceanography, 50: 493-507.

Feely, R. A., Sabine, C. L., Hernández-Ayón, J. M., Ianson, D., and Hales, B. 2008. Evidence for upwelling of corrosive" acidified" water onto the continental shelf. science, 320 : $1490-1492$.

Frigstad, H., Andersen, T., Hessen, D. O., Jeansson, E., Skogen, M., Naustvoll, L.-J., Miles, M. W., et al. 2013. Long-term trends in carbon, nutrients and stoichiometry in Norwegian coastal waters: evidence of a regime shift. Progress in Oceanography, 111: 113-124.

Giordano, M., Beardall, J., and Raven, J. A. 2005. $\mathrm{CO}_{2}$ concentrating mechanisms in algae: mechanisms, environmental modulation, and evolution. Annual Review of Plant Biology, 56: 99-131.

Havenhand, J., Dupont, S., and Quinn, G. P. 2010. Designing ocean acidification experiments to maximise inference. In Guide to best practices for ocean acidification research and data reporting, pp. 67- 80. Ed. by U. Riebesell, V. J. Fabry, L. Hansson, and J.-P. Gattuso. Publications Office of the European Union, Luxembourg.

Hickman, A. E., Moore, C., Sharples, J., Lucas, M. I., Tilstone, G. H., Krivtsov, V., and Holligan, P. M. 2012. Primary production and nitrate uptake within the seasonal thermocline of a stratified shelf sea. Marine Ecology Progress Series, 463: 39-57. 
Hopkins, F. E., and Archer, S. D. 2014. Consistent increase in dimethyl sulfide (DMS) in response to high $\mathrm{CO}_{2}$ in five shipboard bioassays from contrasting NW European waters. Biogeosciences, 11: 4925-4940.

Hopkins, F. E., Turner, S. M., Nightingale, P. D., Steinke, M., Bakker, D., and Liss, P. S. 2010. Ocean acidification and marine trace gas emissions. Proceedings of the National Academy of Sciences, 107: 760-765.

Iglesias-Rodriguez, M. D., Halloran, P. R., Rickaby, R. E., Hall, I. R., Colmenero-Hidalgo, E., Gittins, J. R., Green, D. R., et al. 2008. Phytoplankton calcification in a high- $\mathrm{CO}_{2}$ world. Science, 320: 336-340.

Kirk, J. T. 1994. Light and photosynthesis in aquatic ecosystems, Cambridge University Press.

Kirkwood, D. 1989. Simultaneous determination of selected nutrients in sea water. International Council for the Exploration of the Sea (ICES): CM C:29.

Lange, C. B., Hasle, G. R., and Syvertsen, E. E. 1992. Seasonal cycle of diatoms in the Skagerrak, North Atlantic, with emphasis on the period 1980-1990. Sarsia, 77: 173187.

Langer, G., Nehrke, G., Probert, I., Ly, J., and Ziveri, P. 2009. Strain-specific responses of Emiliania huxleyi to changing seawater carbonate chemistry. Biogeosciences, 6: 26372646.

Lee, P. A., Rudisill, J. R., Neeley, A. R., Hutchins, D., Feng, Y., Hare, C., Leblanc, K., et al. 2009. Effects of increased $p \mathrm{CO}_{2}$ and temperature on the North Atlantic Spring Bloom: III. Dimethylsulfoniopropionate. Marine Ecology Progress Series, 388: 41-49.

Leterme, S. C., Edwards, M., Seuront, L., Attrill, M., Reid, P., and John, A. 2005. Decadal basin-scale changes in diatoms, dinoflagellates, and phytoplankton color across the North Atlantic. Limnology and Oceanography, 50: 1244-1253. 
MacGilchrist, G. A., Shi, T., Tyrrell, T., Richier, S., Moore, C. M., Dumousseaud, C., and Achterberg, E. P. 2014. Effect of enhanced $p \mathrm{CO}_{2}$ levels on the production of dissolved organic carbon and transparent exopolymer particles in short-term bioassay experiments. Biogeosciences, 11: 3695-3706.

Nanninga, H., and Tyrrell, T. 1996. Importance of light for the formation of algal blooms by Emiliania huxleyi. Marine Ecology Progress Series, 136: 195-203.

Passow, U. 2012. The abiotic formation of TEP under different ocean acidification scenarios. Marine Chemistry, 128-129: 72-80.

Poulton, A. J., Stinchcombe, M. C., Achterberg, E. P., Bakker, D. C. E., Dumousseaud, C., Lawson, H. E., Lee, G. A., et al. 2014. Coccolithophores on the north-west European shelf: calcification rates and environmental controls. Biogeosciences, 11: 3919-3940.

Quinn, G. P., and Keough, M. J. 2002. Experimental design and data analysis for biologists, Cambridge University Press.

Ribas-Ribas, M., Achterberg, E. P., Archer, S., Bakker, D. C. E., Clark, D., Hopkins, F. E., Moore, C. M., et al. 2014a. UK Ocean Acidification programme D366 cruise around the British Isles CTD bottle sample measurements. British Oceanographic Data Centre - Natural Environment Research Council, UK. doi:10/thr.

Ribas-Ribas, M., Rérolle, V. M. C., Bakker, D. C. E., Kitidis, V., Lee, G. A., Brown, I., Achterberg, E. P., et al. 2014b. Intercomparison of carbonate chemistry measurements on a cruise in northwestern European shelf seas. Biogeosciences, 11: 4339-4355.

Richier, S., Achterberg, E. P., Dumousseaud, C., Poulton, A. J., Suggett, D. J., Tyrrell, T., Zubkov, M. V., et al. 2014. Phytoplankton responses and associated carbon cycling during shipboard carbonate chemistry manipulation experiments conducted around Northwest European shelf seas. Biogeosciences, 11: 4733-4752.

Riebesell, U., and Tortell, P. D. 2011. Effects of ocean acidification on pelagic organisms and ecosystems. In Ocean acidification. Oxford University Press, Oxford, pp. 99-121. 
Riebesell, U., Zondervan, I., Rost, B., Tortell, P. D., Zeebe, R. E., and Morel, F. M. 2000. Reduced calcification of marine plankton in response to increased atmospheric $\mathrm{CO}_{2}$. Nature, 407: 364-367.

Rost, B., and Riebesell, U. 2004. Coccolithophores and the biological pump: responses to environmental changes. In Coccolithophores, pp. 99-125. Springer.

Schneider, B., Engel, A., and Schlitzer, R. 2004. Effects of depth-and $\mathrm{CO}_{2}$-dependent C: N ratios of particulate organic matter (POM) on the marine carbon cycle. Global Biogeochemical Cycles, 18.

Schulz, K. G., Riebesell, U., Bellerby, R., Biswas, H., Meyerhöfer, M., Müller, M., Egge, J., et al. 2008. Build-up and decline of organic matter during PeECE III. Biogeosciences, 5: $707-718$.

Shi, D., Xu, Y., Hopkinson, B. M., and Morel, F. M. M. 2010. Effect of Ocean Acidification on Iron Availability to Marine Phytoplankton. Science, 327: 676-679.

Sommer, U., Paul, C., and Moustaka-Gouni, M. 2015. Warming and ocean acidification effects on phytoplankton - from species shifts to size shifts within species in a mesocosm experiment. PloS one, 10: e0125239.

Sunday, J. M., Calosi, P., Dupont, S., Munday, P. L., Stillman, J. H., and Reusch, T. B. H. 2014. Evolution in an acidifying ocean. Trends in Ecology \& Evolution, 29: 117-125.

Tyrrell, T., and Achterberg, E. P. 2014. Preface: Field investigation of ocean acidification effects in northwest European seas. Biogeosciences, 11: 7269-7274.

Tyrrell, T., and Merico, A. 2004. Emiliania huxleyi: bloom observations and the conditions that induce them. In Coccolithophores, pp. 75-97. Springer.

Villareal, T. A. 1987. Evaluation of nitrogen fixation in the diatom genus Rhizosolenia Ehr. in the absence of its cyanobacterial symbiont Richelia intracellularis Schmidt. Journal of Plankton Research, 9: 965-971. 
Young, J. R., Poulton, A. J., and Tyrrell, T. 2014. Morphology of Emiliania huxleyi coccoliths on the northwestern European shelf - is there an influence of carbonate chemistry? Biogeosciences, 11: 4771-4782. 


\begin{tabular}{|c|c|c|c|c|c|c|c|}
\hline Groups & Environmental variables & Units & Minimum & Maximum & Aver: & ge & \pm SD \\
\hline \multirow{5}{*}{ Physical } & Sea floor depth (SFD) & $\mathrm{m}$ & 38.5 & 4758.4 & 417.0 & \pm & 1093.7 \\
\hline & Temperature (Temp) & ${ }^{\circ} \mathrm{C}$ & 10.3 & 16.2 & 13.6 & \pm & 1.2 \\
\hline & Salinity (Sal) & dimensionless & 28.7 & 35.8 & 34.5 & \pm & 1.6 \\
\hline & Mixed layer depth (MLD) & $\mathrm{m}$ & 2.0 & 131.0 & 27.1 & \pm & 24.0 \\
\hline & Euphotic zone depth (Zeup) & $\mathrm{m}$ & 15.5 & 58.0 & 27.3 & \pm & 8.1 \\
\hline \multirow{9}{*}{$\begin{array}{l}\text { Carbonate } \\
\text { chemistry }\end{array}$} & Mixed-layer average irradiance $\left(\mathrm{Ed}^{\mathrm{ML}}\right)$ & mol PAR $\mathrm{m}^{-2} \mathrm{~d}^{-1}$ & 1.7 & 31.0 & 11.8 & \pm & 7.2 \\
\hline & Dissolved inorganic carbon (DIC) & $\mu \mathrm{mol} \mathrm{kg} \mathrm{kg}^{-1}$ & 1920.8 & 2133.6 & 2079.1 & \pm & 39.7 \\
\hline & Total Alkalinity $\left(\mathrm{A}_{\mathrm{T}}\right)$ & $\mu \mathrm{mol} \mathrm{kg}{ }^{-1}$ & 2121.9 & 2352.0 & 2312.8 & \pm & 47.8 \\
\hline & ${ }^{\dagger}$ Fugacity of carbon dioxide $\left(f \mathrm{CO}_{2}\right)$ & $\mu \mathrm{atm}$ & 274.0 & 395.7 & 347.9 & \pm & 27.0 \\
\hline & ${ }^{\dagger}$ Bicarbonate $\left(\mathrm{HCO}_{3}^{-}\right)$ & $\mu \mathrm{mol} \mathrm{kg}{ }^{-1}$ & 1760.8 & 1963.6 & 1897.9 & \pm & 38.4 \\
\hline & ${ }^{\dagger}$ Carbonate $\left(\mathrm{CO}_{3}{ }^{2-}\right)$ & $\mu \mathrm{mol} \mathrm{kg}{ }^{-1}$ & 136.7 & 191.8 & 167.6 & \pm & 12.4 \\
\hline & ${ }^{\dagger}$ Calcite saturation state $\left(\Omega_{\text {calcite }}\right)$ & dimensionless & 3.3 & 4.5 & 4.0 & \pm & 0.3 \\
\hline & ${ }^{\dagger}$ Aragonite saturation state $\left(\Omega_{\text {aragonite }}\right)$ & dimensionless & 2.1 & 2.9 & 2.6 & \pm & 0.2 \\
\hline & ${ }^{\dagger} \mathrm{H}^{+}$ & $\mu \mathrm{mol} \mathrm{kg} \mathrm{kg}^{-1}$ & $6.5092 \mathrm{E}-09$ & 8.8975E-09 & $8 \mathrm{E}-09$ & \pm & $5 \mathrm{E}-10$ \\
\hline \multirow{5}{*}{ Nutrients } & Nitrate and Nitrite $\left(\mathrm{NO}_{3}\right)$ & $\mu \mathrm{mol} \mathrm{L}$ & 0.10 & 4.61 & $0 . \overline{7} \overline{6}$ & \pm & 1.11 \\
\hline & Silicic acid $\left(\mathrm{Si}(\mathrm{OH})_{4}\right)$ & $\mu \mathrm{mol} \mathrm{L}{ }^{-1}$ & 0.10 & 3.63 & 1.02 & \pm & 0.90 \\
\hline & Phosphate $\left(\mathrm{PO}_{4}\right)$ & $\mu \mathrm{mol} \mathrm{L}{ }^{-1}$ & 0.02 & 0.38 & 0.07 & \pm & 0.07 \\
\hline & $\mathrm{Si}^{*}$ & dimensionless & -1.67 & 2.25 & 0.26 & \pm & 0.83 \\
\hline & $\mathrm{N}^{*}$ & dimensionless & -2.84 & 3.67 & -0.32 & \pm & 1.00 \\
\hline
\end{tabular}

Table 1. The range of environmental variables over the NW European shelf cruise, categorised into forcing variable groups. ${ }^{\dagger}$ denotes calculated from dissolved inorganic carbon and total alkalinity. 


\begin{tabular}{ll}
\hline Statistical test/methods & Abbreviation \\
\hline Principal components analysis & PCA \\
Cluster + Similarity Percentages & Cluster +SIMPER \\
Principal co-ordination analysis & PCO \\
Analysis of similarities & ANOSIM \\
Mantel Test & RELATE analysis \\
Distance-based linear model & DISTLM \\
Multiple linear regression model & LM \\
Generalized linear model & GLM \\
\hline
\end{tabular}

Table 2. List of statistical test and methods used as outlined in detail in Section 2.4 


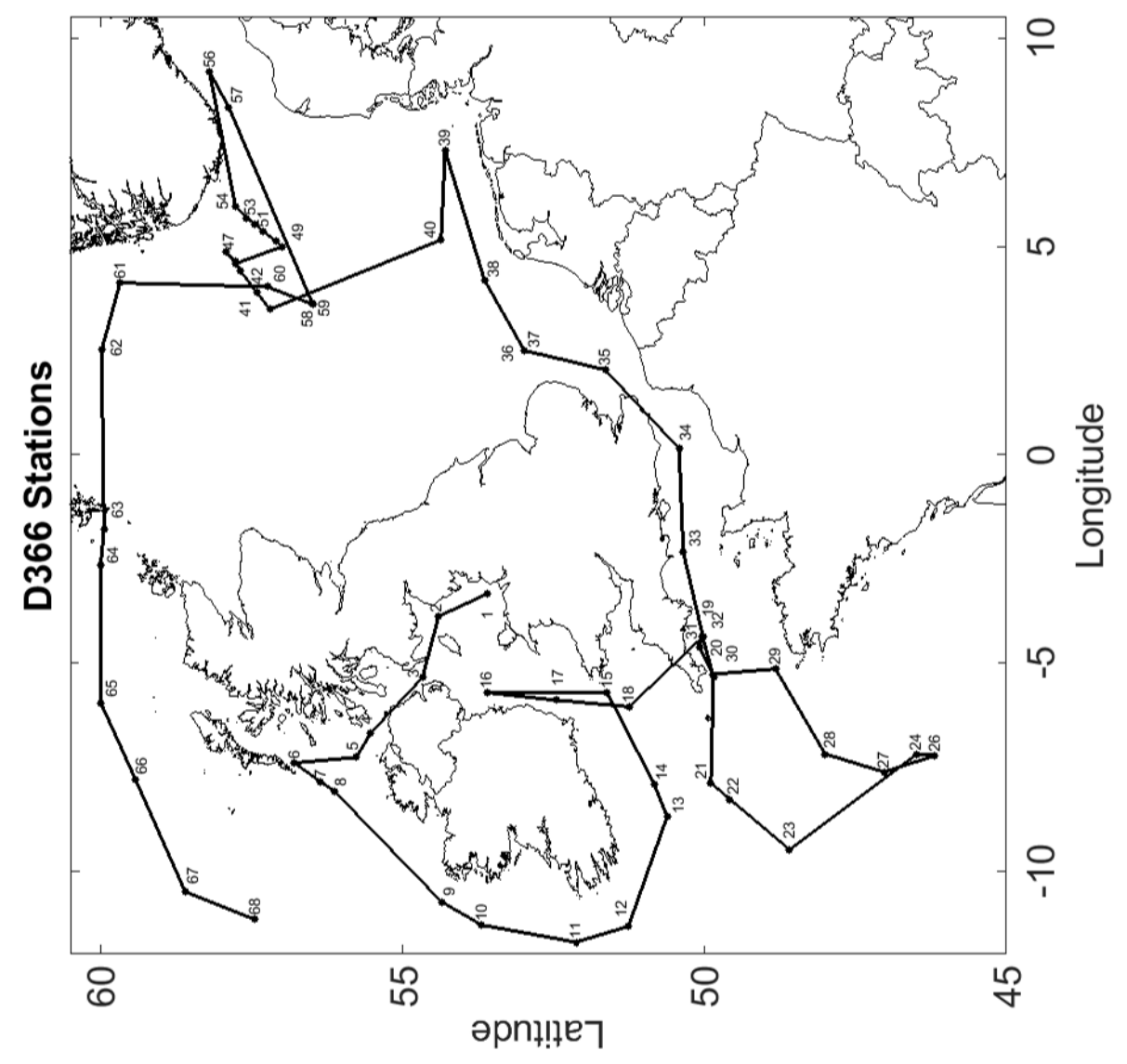



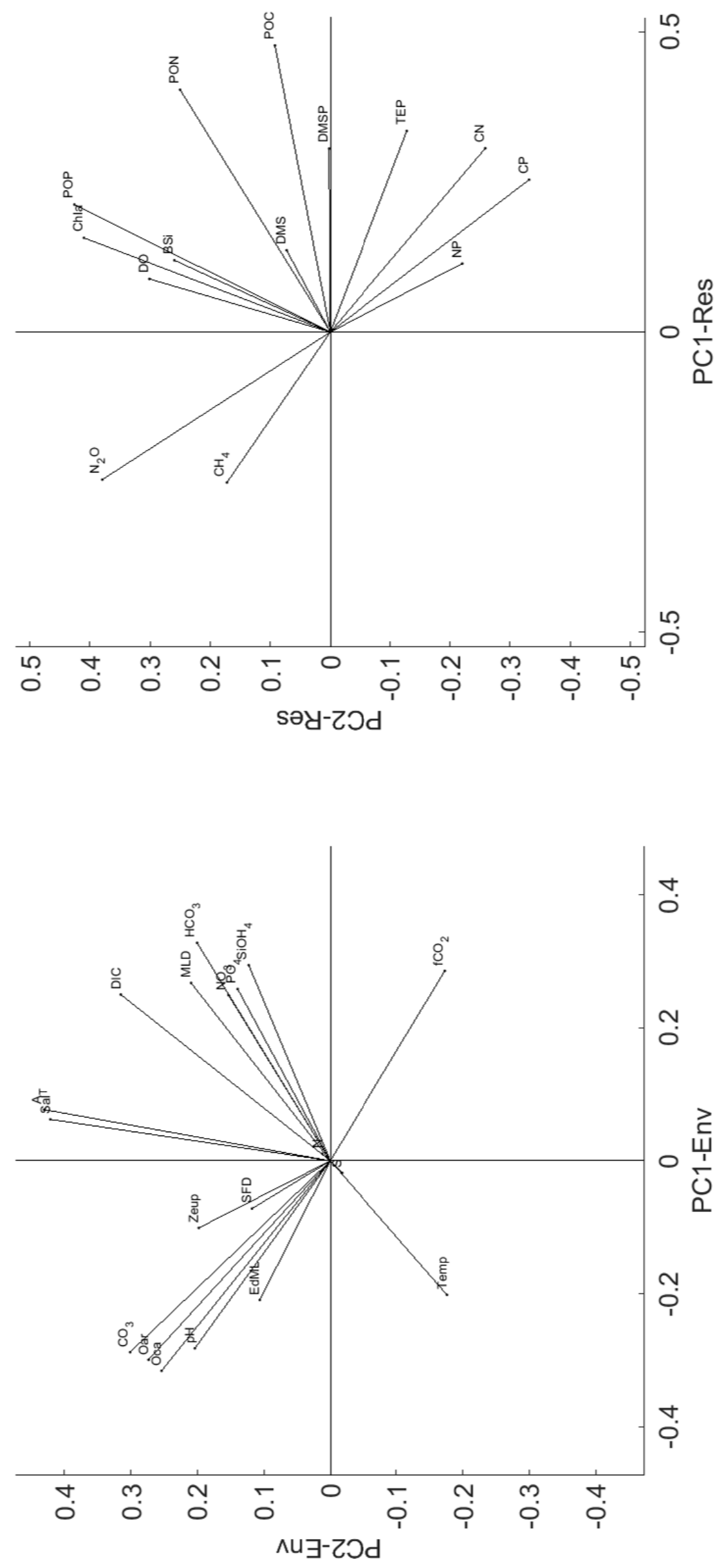


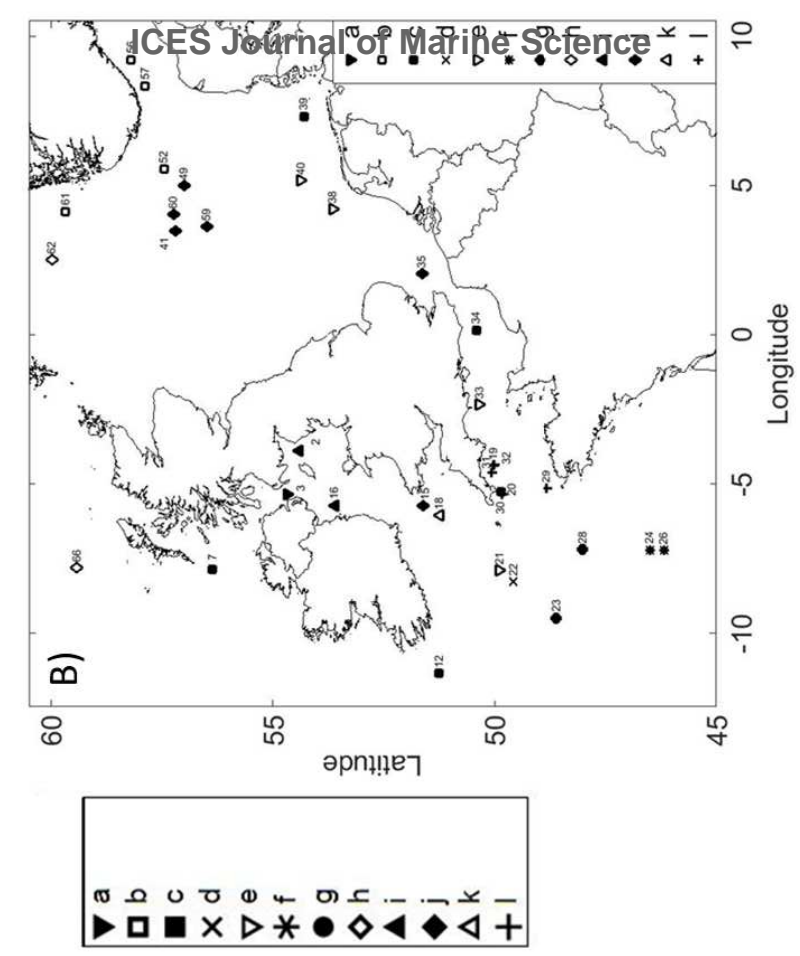

Page 40 of 43

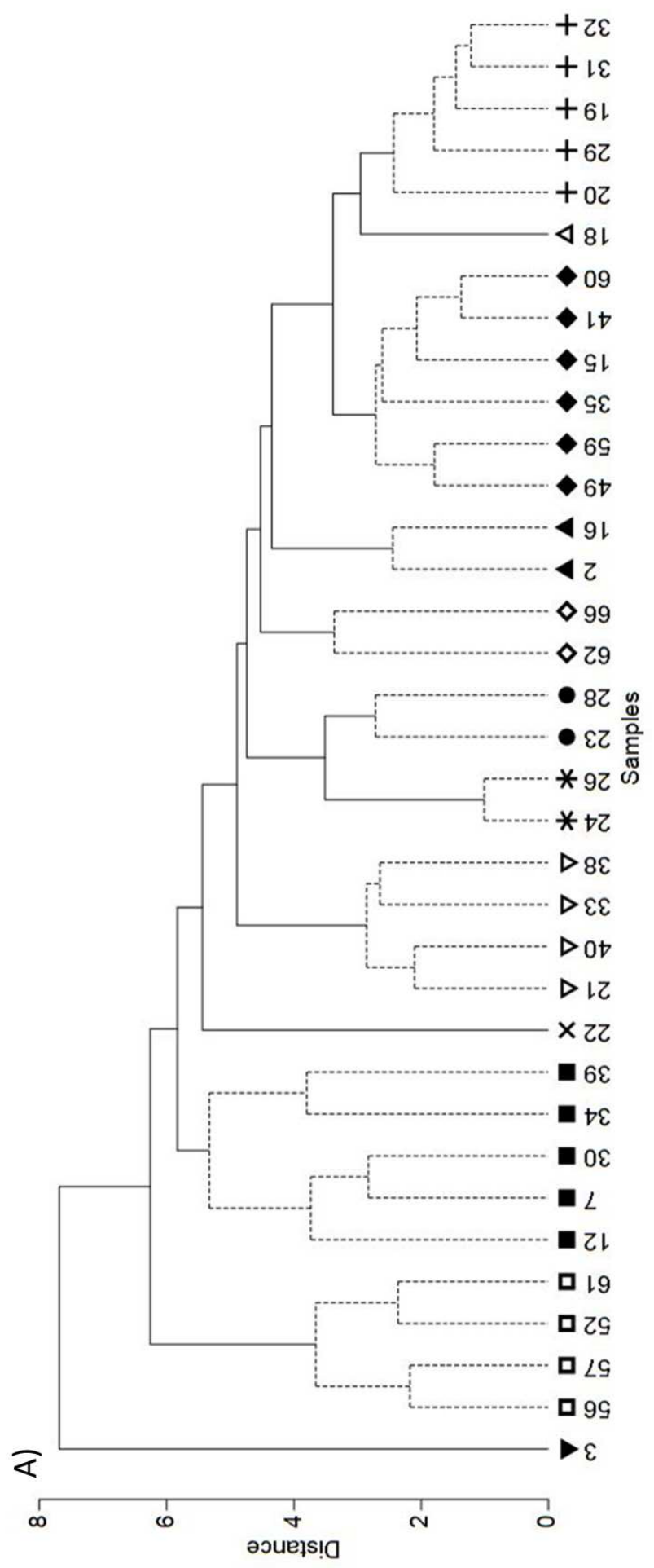



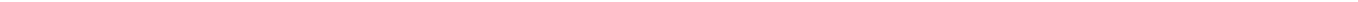


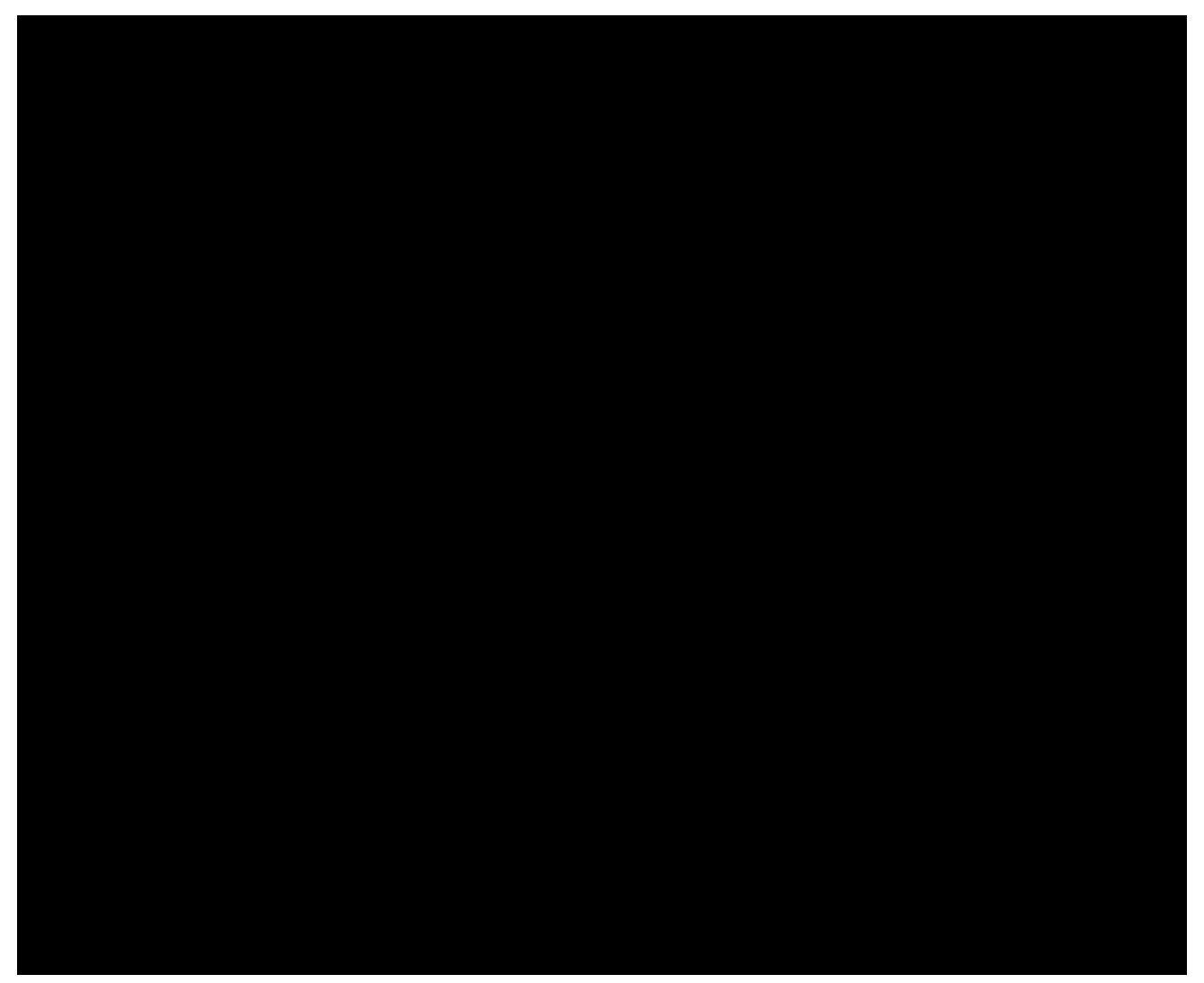

Figure 6. Schematic summarizing how the variance in phytoplankton community composition on the northwest European shelf is open between different forcing factors (hydrography, nutrients, carbonate chemistry): (A) total phytoplankton (without unidentified naked dinoflagellates), (B) coccolithophores, (C) dinoflagellates (without unidentified naked dinoflagellates) and (D) diatom community structure across the NW European shelf. Those environmental variables that are underlined within each group denote the subset of variables within each forcing group that explain the most variance of the community structure. Bold variables denote the best overall subset of variables across the 3 groups to explain the variance within the community structure.

$400 \times 329 \mathrm{~mm}(150 \times 150 \mathrm{DPI})$ 